\title{
Research Paper: Effectiveness of Cognitive-Behavioral Group Therapy on Guilt Feeling Among Family Caregivers of Patients With Alzheimer's Disease
}

\author{
Masoumeh Mahmoudi ${ }^{1}$, Parvaneh Mohammadkhani ${ }^{\star}$, Bagher Ghobari Bonab ${ }^{3}$, Fariborz Bagheri ${ }^{1}$ \\ 1. Department of Psychology, Faculty of Humanities and Social Sciences, Science and Research Branch, Islamic Azad University, Tehran, Iran \\ 2. Department of Clinical Psychology, University of Social Welfare and Rehabilitation Sciences, Tehran, Iran. \\ 3. Department of Psychology, Faculty of Psychology \& Education, University of Tehran, Tehran, Iran.
}

\begin{tabular}{|c|c|}
\hline $\begin{array}{l}\text { Use your device to scan } \\
\text { and read the article online }\end{array}$ & dtat on: Mahmoudi, M., Mohammadkhani, P., Ghobari Bonab, B., \& Bagheri, F. Effectiveness of Cognitive-Behavioral \\
\hline 口ifitiv & $\begin{array}{l}\text { Group Therapy on Guilt Feeling Among Family Caregivers of Patients With Alzheimer's Disease. Journal of Practice in Clini- } \\
\text { cal Psychology, 5(3), 203-210. https://doi.org/10.18869/acadpub.jpcp.5.3.203 }\end{array}$ \\
\hline 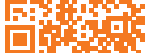 & dol $:$ https://doi.org/10.18869/acadpub.jpcp.5.3.203 \\
\hline
\end{tabular}

\section{Article info:}

Received: 05 Mar. 2017

Accepted: 03 Jun. 2017

\section{Keywords:}

Cognitive-behavioral group therapy, Guilt feeling, Caregivers, Alzheimer

\section{ABSTRACT}

Objective: This study aimed at investigating the effectiveness of cognitive-behavioral group therapy on guilt feeling among family caregivers of patients with Alzheimer's disease.

Methods: This research was a quasi-experimental study where in the pre-test and post-test control group design was employed. The statistical population of this study consisted of the female family caregivers of the Alzheimer's patients who were referred to the Iran Alzheimer's Association in 2012. Among this population, 32 volunteers were selected via convenience sampling method and were then randomly assigned into two experimental and control groups. The participants of both groups filled in the guilt feeling questionnaire and caregiver guilt questionnaire in both the pre-test and post-test phases. The therapy program lasted for 14 sessions. Multivariate regression analysis and covariance analysis were used to analyze the data.

Results: The results showed that the levels of overall guilt and caregiver guilt had significantly decreased in the experimental group after the exposure of this group to cognitive-behavioral group therapy as compared to the pre-test and control group $(\mathrm{P}<0.01)$.

Conclusion: Based on the findings of this study, cognitive-behavioral group therapy was found to reduce the overall guilt and caregiver guilt among the family caregivers of Alzheimer's patients. This therapeutic method is recommended as a cost-effective treatment to be used by family caregivers of Alzheimer's patients.

\section{Introduction}

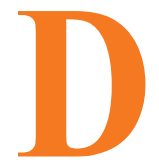

ue to the increasing population of the elderly, an increasing incidence of Alzheimer's disease has been marked as a major health concern in the world. In 2006, about 27 million people worldwide were reported to be suffering from Alzheimer's disease, and this number is expected to quadruple by 2050 (Brookmeyer, Johnson, Ziegler, \& Arrighi, 2007).

Alzheimer's disease is the most common type of dementia and is defined as a dysfunction in one or more cognitive domains that interferes with the occupational

\section{* Corresponding Author:}

Parvaneh Mohammadkhani, PhD

Address: Department of Clinical Psychology, University of Social Welfare and Rehabilitation Sciences, Tehran, Iran.

Tel: +98 (912) 3210354

E-mail: shohremahmoodi56@gmail.com 
and social performance. Attention deficit, decisionmaking disorder, planning disorder, abstract thinking, semantic memory dysfunction, personality change, and delusions also exist in these patients (Pocnet, Rossier, Antonietti \& von Gunten, 2013). The individuals with Alzheimer's disease sometimes hold a cynical view of their caregivers and show hostile behaviors. It is often very stressful for the caregivers to provide these patients with care. As this disease progresses, patients face numerous problems of challenging management (Butcher, Hooley \& Mineka, 2013).

One of the consequences of long-term care is the creation of guilt feelings in caregivers. Several studies have been undertaken to evaluate the guilt feeling among the family caregivers of Alzheimer's patients. The findings of these studies (Brodaty \& Donkin, 2009; Gonyea, Paris, \& de Saxe Zerden, 2008; Croog, Burleson, Sudilovsky, \& Baume, 2006), were indicative of an existing high level of guilt that leads to increased care burden in the caregivers of patients with Alzheimer's disease.

The study of guilt feeling is an important and functional part of psychology and is known as a self-conscious emotion, which is found in social communication. Guilt feeling will increase as a result of worries and concerns about others, the self, and the undertaken actions. It is an emotion associated with self-blame and the need for punishment and is defined as a violation of the norms and values that have been inherited to us by our ancestors (Egan, Wade, \& Shafran, 2011).

In their study, Bruno et al. (2009) have pointed out that guilt feeling is a maladaptive emotion that is not corrected easily and produces stress, inhibition, and severe psychological trauma to people. Based on his own research findings, Beck has argued that guilt feeling is a stronger index for predicting the incidence of intrusive thoughts and impulses in comparison with anxiety and depression (Beck, 1967).

Due to the devastating effects of guilt feeling on people's mental health, the use of intervention and treatment is necessary. Inter-ventional programs are likely to reach success if they are founded upon theory and research support. In relation to adults, this type of intervention can be presented based on cognitive-behavioral approach (Seligman, Schulman, \& Tryon, 2007). Emphasis on the identification of false, negative, extreme, and unrealistic beliefs is effective in patients' emotions and behaviors; and the modification of these underlying beliefs will be possible by using cognitive-behavioral group techniques (Bieling, McCabe, \& Antony, 2006).
Few studies have been carried out on the impact of cognitive-behavioral group therapy on guilt feeling in different statistical populations. The findings of these studies (Ikeda, Hayashi \& Kamibeppu, 2014; Hedman, Ström, Stünkel, \& Mörtberg, 2013; Karlin et al. 2012) reported the effectiveness of cognitive-behavioral group therapy on guilt feeling. Unfortunately, there is a paucity of research on the impact of treatment on guilt feeling. Thus, the present study was carried out to contribute to this research gap. Research has shown that guilt feeling is highly seen in caregivers of Alzheimer's patients and leads to the incidence of increased burden of care, stress, anxiety and depression in them. This study aimed to assess the effectiveness of cognitive-behavioral group therapy on the overall guilt feeling among family caregivers of patients with Alzheimer's disease.

\section{Methods}

This research was a quasi-experimental study, in which the pre-test and post-test control group design was employed. The target population of this study consisted of the female family caregivers of the Alzheimer's patients who were referred to the Alzheimer's Association of Iran (located in Tehran) in 2012. The sample size of 16 participants for each group (control and experimental groups) was found to be suitable through Cohen's formula. In addition, considering an effect size equivalent to $\alpha=5 \%$ and 0.6 and a test power equivalent to 91 , the sample size was calculated. Thus, a total of 32 participants were considered for the study.

For sample selection, the available caregivers who volunteered to attend the therapy sessions completed the questionnaire. Among these respondents, 32 subjects who had responded to the questionnaire well and had satisfied the inclusion criteria were selected as the sample units. Then, they were randomly assigned to the experimental group (under cognitive-behavioral group therapy) and control group in equal numbers. The participants signed the informed consent to participate in the research, and they were ensured that their information would be kept strictly confidential and that the results of the study would be released in the form of general conclusions and statistics. In addition, it was decided that the control group would participate in the course of cognitive-behavioral group therapy after the end of the present study.

The inclusion criteria were as follows: 1) The participants were required to be the family and relatives who are the caregivers of Alzheimer's patients. 2) Female gender of the caregiver (The findings of few other studies (Losada, Márquez-González, Peñacoba, \& Romero- 
Moreno, 2010; Croog, Burleson, Sudilovsky, \& Baume, 2006; Mahoney, Regan, Katona, \& Livingston, 2005; McConaghy \& Caltabiano, 2005) showed that women encompass a greater percentage of the population of family caregivers of Alzheimer's patients; similarly, the psychological side effects caused by the burden of caring in women is higher than that in men). 3) The participants were required to hold at least the education degree of junior high school (due to the active and participatory nature of cognitive-behavioral therapy and the fulfillment of daily assignments, some level of individuals' ability is required to identify thoughts and emotions and perceive the cognitive-behavioral approach). 4) The individuals should not have suffered from any mental illness before the start of the caregiving.

The researcher constructed a guilt feeling questionnaire that was used to assess the overall guilt feeling. This questionnaire has been developed and validated by Alavi (2006) and contains 38 items. It evaluates guilt feeling in two subscales, namely pathologic guilt feeling and nonpathologic guilt feeling. Scoring method: The questionnaire items were scored based on a five-point Likert scale (strongly agree, agree, neutral, disagree, and strongly disagree). Scoring was done in such a way that the five alternatives (strongly agree, agree, neutral, disagree, and strongly disagree) were assigned 5, 4, 3, 2, and 1 scores, respectively for the sentences in line with the question's objective. In this questionnaire, the questions numbered $37,4,5,8,11,14,17,18,20,24,27,31$, and 2 were nonaligned and the other questions were aligned. The score of 125 represented the maximum pathologic guilt feeling while the score of 50 represented the absence of any pathologic guilt feeling. Cronbach's alpha coefficient of this questionnaire equaled 0.75 , which represented its stability and internal consistency.

Caregiver Guilt Questionnaire (CGQ) was used to assess guilt feeling among the caregivers. This is a researcher-constructed questionnaire rooted in Salkovskis's cognitive theory, and its main focus was on the impact of caregivers' excessive sense of responsibility. Salkovskis believed that the maladaptive schema of excessive responsibility in patients acts as a continuing factor of the vicious circle disorder. Guilt feeling and sense of responsibility are experienced together and the people who feel responsible because of their negative thoughts or for the non-prevention of the damage associated with these thoughts are likely to experience feelings of guilt for holding such thoughts (Salkovskis, 1989).

The scale contains 22 items and three subscales, namely caregiver's guilt about the care recipient, caregiver's guilt about other family members, and guilt about selfcare. The items numbered 1, 4, 5, 6, 7, 8, 9, 10, 12, 13, 14,17 , and 20 represent the subscale of caregiver's guilt about the care recipient. In addition, the items numbered $2,15,16,18$, and 19 represent the subscale of caregiver's guilt about other family members. Finally, the items numbered 3, 11, 21, and 22 represent the subscale of guilt about self-care.

The above-mentioned questionnaire has been developed based on a Likert scale such that each participant should select an alternative from one of the five options, namely always, often, sometimes, hardly, and never. Scoring is done in such a way that the alternatives, i.e., always, often, sometimes, hardly, and never, are assigned 5, 4, 3, 2, and 1 scores, respectively, for the sentences in line with the question's objective. In this questionnaire, the items numbered 3, 6, 11, and 22 are non-aligned and the other items are in line with the question's objective. In CGP, the scores 110 and 34 were the maximum and minimum possible scores of the scale, respectively. The score 34 indicated the absence of caregiver guilt. For the assessment of the validity of the scale, the face validity and content validity of the scale were found to be acceptable using the opinions of some relevant specialists and experts.

Cronbach's alpha coefficient was used to calculate the reliability of the questionnaire. It is noteworthy that the Cronbach's alpha coefficient of the questionnaire was calculated after the collection of 30 questionnaires that had been randomly distributed among the caregivers. This coefficient was found to be 0.77 , which indicated the stability and internal consistency of the questionnaire. A researcher constructed a demographic questionnaire that was used in order to obtain the individual information of the participants.

The participants responded to guilt-related questionnaires before the initiation of the treatment (pre-test). Then, the caregivers in the control and experimental groups were asked to respond to guilt scales after the passage of five months from the start of the therapeutic sessions (post-test). The quasi-experimental intervention of cognitive-behavioral group therapy was applied to the experimental group for fourteen 180-minute sessions in the center of Tehran Alzheimer's Association while the control group received no intervention. The researcher constructed cognitive-behavioral therapy that was used in all treatment processes. It was noteworthy that two members of each group resigned from participation in the sessions for personal reasons during the therapy sessions. The researcher constructed cognitive-behavioral 
group therapy sessions for the caregivers in the experimental group as follows:

First session: It contained the following: acquaintance with the members and the statement of the rationale and objectives of the training sessions, description of Alzheimer's disease and its impact on the caregivers' lifestyle in the form of chronic stress, discussion on the roots and internal and external factors causing stress, and explanation of the guilt feeling as an internal cause of failure and a stressor to the members.

Second session: The members became familiar with how to understand their own issues, five aspects of life experiences were described to them, and then, the members filled out worksheets on the perception of their own issues after practicing the understanding of their issues.

Third session: The relationship of thoughts with feelings, behavior, and physical reactions was explained to the members. Then, the members began to fill out the worksheets in this relation.

Fourth session: The members became familiar with how to detect and grade mood states; and some practices were relevantly presented in the groups.

Fifth session: The methods of recognizing extreme and unrealistic thoughts were taught to the caregivers, as well as the cognitive errors and their role in the production of guilt feelings.

Sixth session: It was taught how to reappraise thoughts and challenge cognitive thoughts and deviations, especially all-or-nothing thoughts. Extreme generalization and mind reading were also talked about as solutions to challenge irrational thoughts of people. Later in this session, the members completed the relevant worksheets.

Seventh session: The advantages and disadvantages of perfectionist thoughts and fight with musts and absolutism were explained. In the end, the members filled out the related worksheets.

Eighth session: They were taught how to overcome the guilt feeling via the assessment of the severity of behaviors, determination of personal responsibility, and practice of responsibility pie charts.

Ninth session: Problem-solving methods and appropriate responses to the patient's maladaptive behavior were discussed. Then, the members discussed and exchanged their experiences in this field.
Tenth session: Anger perception and management were taught and the group members taught each other the suitable approaches to anger management in the caregiving process.

Eleventh session: Time management was taught with the emphasis on goal setting, daily to-do list, nursing responsibilities in regard to patients, spending time with family and friends, leisure and office tasks, prioritization based on importance and urgency, self-care and behavioral activation, and weekly planning on the barriers to time management.

Twelfth session: The following themes were the major focus of this session: the clarification of values and prioritization of these values in the past, present, and future for the group members; teaching of communication skills and assertiveness through completion of worksheets and explanation of rights charter to the members; and the use of problem-solving techniques in the face of conflicts (finding practical solutions, role-play games).

Thirteenth Session: The variety of social supports and understanding of their benefits were explained, and the personal resources and community resources were also discussed with the aim of the group's understanding of the importance of the social resources that constructively assist the individual in sadness, progress, etc.

Fourteenth session: This session included an overview and practice of the skills learned in previous sessions.

\section{Results}

The data in this study were analyzed using SPSS18 software via descriptive statistics (central and dispersion indexes such as mean and standard deviation as well as graphs and data tables) and inferential statistics (ANCOVA and MANCOVA).

According to the figures in Table 1, the mean scores of caregiver guilt and overall guilt were different between the pre-test and post-test in the experimental group. In fact, the participants' scores in the experimental group were found to be reduced in the post-test after the implementation of the treatment. In the control group, the mean scores of guilt subscales were close to each other in the two stages, before and after implementation of the treatment. This indicates that there is no significant difference between the pre-test and post-test scores of the participants in this regard. Table 2 shows that all the four tests are significant at the significance level of 0.01 . Therefore, the multivariate effect of the experimental 
Table 1. Mean and SD of CGQ and guilt feeling questionnaire in the pre-test and post-test

\begin{tabular}{|c|c|c|c|c|c|}
\hline & \multirow{2}{*}{ Phase } & \multicolumn{2}{|c|}{ Experimental Group } & \multicolumn{2}{|c|}{ Control Group } \\
\hline & & Mean & SD & Mean & SD \\
\hline \multirow{3}{*}{ Caregiver guilt } & Pre-test & 94.46 & 9.422 & 95.62 & 6.602 \\
\hline & Post-test & 57.31 & 8.741 & 97.11 & 7.253 \\
\hline & Follow-up & 52.57 & 2.901 & 113.15 & 6.902 \\
\hline \multirow{2}{*}{ Overall guilt feeling } & Pre-test & 114.57 & 18.080 & 108.12 & 12.747 \\
\hline & Post-test & 79.43 & 11.050 & 112.23 & 11.425 \\
\hline
\end{tabular}

Table 2. MANCOVA comparison of the multivariate effect of the experimental and control groups on the interaction of guilt variables

\begin{tabular}{cccccc}
\hline Test & Statistic & F & Df 1 & Df 2 & Sig. \\
\hline Pillai's trace & 0.957 & 103.75 & 3 & 14 & 0.001 \\
\hline Wilk's lambda & 0.043 & 103.75 & 3 & 14 & 0.001 \\
\hline Hotelling's trace & 22.223 & 103.75 & 3 & 14 & 0.001 \\
\hline Roy's largest root & 22.223 & 103.75 & 3 & 14 & 0.001 \\
\hline
\end{tabular}

and control groups have been significant on the interaction between the variables and guilt components. In Table 3, analysis of covariance was used separately to compare the experimental and control groups in terms of caregiver guilt, overall guilt, and its components, i.e., pathologic and nonpathologic guilt feeling. According to the tabular data, it is concluded that there has been a significant difference between the control and experimental groups in all four components separately. Hence, it can be concluded that cognitive-behavioral group therapy

Table 3. Covariance analysis of the dependent variables: Overall guilt feeling in the post-test

\begin{tabular}{|c|c|c|c|c|c|c|c|}
\hline Variable & Source & Sum of Squares & Df & Mean Square & $\mathbf{F}$ & Sig. & Eta Squared \\
\hline \multirow{3}{*}{ Pathologic } & Pre-test & 244.171 & 1 & 244.171 & 3.484 & 0.074 & 0.127 \\
\hline & Group & 5493.108 & 1 & 5493.108 & 78.388 & 0.001 & \\
\hline & Error & 1681.813 & 24 & 70.076 & & & \\
\hline \multirow{3}{*}{$\begin{array}{l}\text { Nonpatho- } \\
\text { logic }\end{array}$} & Pre-test & 4.137 & 1 & 4.137 & 0.273 & 0.606 & 0.011 \\
\hline & Group & 129.968 & 1 & 129.968 & 8.576 & 0.007 & 0.263 \\
\hline & Error & 363.715 & 24 & 15.155 & & & \\
\hline \multirow{3}{*}{$\begin{array}{l}\text { Overall } \\
\text { guilt }\end{array}$} & Pre-test & 170.371 & 1 & 170.371 & 1.371 & 0.253 & 0.054 \\
\hline & Group & 7407.739 & 1 & 7407.739 & 59.592 & 0.011 & 0.713 \\
\hline & Error & 2983.365 & 24 & 124.307 & & & \\
\hline \multirow{3}{*}{$\begin{array}{l}\text { Caregiver } \\
\text { guilt }\end{array}$} & Pre-test & 480.853 & 1 & 480.853 & 31.634 & 0.001 & 0.625 \\
\hline & Group & 3742.441 & 1 & 3742.441 & 246.209 & 0.001 & 0.928 \\
\hline & Error & 288.805 & 19 & 15.200 & & & \\
\hline
\end{tabular}


has exerted a significant effect on the reduction of overall guilt feeling and caregiver guilt.

\section{Discussion}

The results of different studies showed that there are high levels of guilt feeling among family caregivers of Alzheimer's patients. However, only a few studies, if any, have attempted to decrease the guilt level in family caregivers of Alzheimer's patients. Accordingly, this study was conducted for the first time with the aim of investigating the effectiveness of cognitive-behavioral group therapy in the overall guilt feeling and caregiver guilt among family caregivers of Alzheimer's patients.

The obtained findings showed that cognitive-behavioral group therapy has a significant impact on reducing the symptoms of overall guilt feeling and caregiver guilt feeling. These findings of the present study are partly in consistent with the findings of the studies conducted by Ikeda et al. (2014), Karlin et al. (2013), Hedman et al. (2013), and Karlin et al. (2012). To explain these findings, one can refer to various reasons, one of which is the beneficial effects of group therapy. Group therapy helps people learn effective social skills and then test their learned techniques on other group members. They feel comfortable and confident when they observe other individuals' problems that are similar to or even more severe than their own problems (Sharf, 2015).

Another reason accounting for this finding is the consideration of the role of the used cognitive and behavioral strategies because the cognitive approach acknowledges that stressful situations often continue by biased and extremist thoughts and are intensified by distortions in data processing. This approach is based on the belief that people pay attention to the data consistent with their own previous convictions in a selective fashion (Leahy, 2017).

To overcome guilt feeling does not mean that any negative emotions should not be at play when something is not right, but it means that a great amount of responsibility should be accepted. In this study, it was attempted to identify irrational and dysfunctional thoughts that provoke feelings of guilt. In addition, the caregivers gained insight into the role of these thoughts and tried to replace them with rational thoughts via cooperation. This is feasible with the assessment of the severity of behaviors, determination of the level of personal responsibility, and the behavioral strategies used in this study such as time management skills, anger management, and assertion (Antoni, Ironson \& Schneiderman, 2007).
The modification of cognitive assessments and the exercises presented for the integration of learned techniques with real life situations could lead to the mitigation of guilt feeling in caregivers. Since the self is responsible for negative consequences and the self-attributions of permanent, common, and continuous responsibility lie within the individual, the guilt feeling arising from the sense of responsibility has several negative consequences (Seligman, 1990). Health psychology is aimed at preventing the incidence of mental disorders, diagnosis and early treatment, and assist the problems caused by mental disorders in a wide range (Sappington, 1989).

Given the positive results of cognitive-behavioral group therapy in this research, it is possible to make use of caregivers in Alzheimer's associations in order to overcome feelings of guilt and prevent more extensive damage. The modification of cognitive assessment and the provided training towards the integration of learned techniques with real life situations could lead to reduced guilt feeling in caregivers.

Finally, it is pointed out that although the present approach is effective based on research findings, discretion should be exercised in the generalization of these results to men and other parts of the country due to the assignment of the sample group solely to females in this study and considering the study location as well. The unavailability of follow-up phase due to time constraints was another limitation of this study. Therefore, it is recommended that comparative studies between male and female family caregivers be conducted on larger samples in other regions of the country with the inclusion of the follow-up phase. In this way, a higher degree of generalizability of the results can be ensured.

\section{Acknowledgments}

The present article has been extracted from the first author's MSc. thesis in the Department of Psychology, Faculty of Humanities and Social Sciences, Science and Research Branch, Islamic Azad University, Tehran. The researchers find it necessary to appreciate the sincere cooperation and assistance of the staff of the Alzheimer's Association of Iran and all the participants in this research.

\section{Conflict of Interest}

The authors declared no conflicts of interest. 


\section{References}

Alavi, Z. (2006). [Investigating the relationship between the perceived guilt and the perception of God with depression and hope in cancer patients (Persian)] (MSc. Thesis) Tehran: Al-Zahra University.

Antoni, M. H., Ironson, G., \& Schneiderman, N. (2007). Cognitivebehavioral stress management:Workbook. Oxford: Oxford University Press. doi: 10.1093/med:psych/9780195327908.001.0001

Beck, A. T. (1967). Depression: Clinical, experimental, and theoretical aspects. Pennsylvania: University of Pennsylvania Press.

Bieling, P. J., McCabe, R. E., \& Antony, M. M. (2006). Cognitivebehavioral therapy in groups. New York: Guilford Press.

Brodaty, H., \& Donkin, M. (2009). Family caregivers of people with dementia. Dialogues in clinical neuroscience, 11(2), 217-28. PMCID: PMC3181916

Brookmeyer, R., Johnson, E., Ziegler-Graham, K., \& Arrighi, H. M. (2007). Forecasting the global burden of Alzheimer's disease. Alzheimer's \& Dementia, 3(3), 186-91. doi: 10.1016/j. jalz.2007.04.381

Bruno, S., Lutwak, N., \& Agin, M. A. (2009). Conceptualizations of guilt and the corresponding relationships to emotional ambivalence, self-disclosure, loneliness and alienation. Personality and Individual Differences, 47(5), 487-91. doi: 10.1016/j. paid.2009.04.023

Butcher, J. N., Hooley, J. M., Mineka, S. M. (2013). Abnormal psychology. New Jersey: Pearson Education.

Croog, S. H., Burleson, J. A., Sudilovsky, A., \& Baume, R. M (2006). Spouse caregivers of Alzheimer patients: Problem responses to caregiver burden. Aging \& Mental Health, 10(2), 87-100. doi: $10.1080 / 13607860500492498$

Egan, S. J., Wade, T. D., \& Shafran, R. (2011). Perfectionism as a transdiagnostic process: A clinical review. Clinical Psychology Review, 31(2), 203-12. doi: 10.1016/j.cpr.2010.04.009

Gonyea, J. G., Paris, R., \& de Saxe Zerden, L. (2008). Adult daughters and aging mothers: The role of guilt in the experience of caregiver burden. Aging \& Mental Health, 12(5), 55967. doi: $10.1080 / 13607860802343027$

Gutiérrez-Maldonado, J., \& Caqueo-Urízar, A. (2007). Effectiveness of a psycho-educational intervention for reducing burden in latin american families of patients with schizophrenia. Quality of Life Research, 16(5), 739-47. doi: 10.1007/s11136-0079173-9

Hedman, E., Ström, P., Stünkel, A., \& Mörtberg, E. (2013). Shame and guilt in social anxiety disorder: Effects of cognitive behavior therapy and association with social anxiety and depressive symptoms. PLoS ONE, 8(4), 61713. doi: 10.1371/journal. pone. 0061713

Ikeda, M., Hayashi, M., \& Kamibeppu, K. (2014). The relationship between attachment style and postpartum depression. Attachment \& Human Development, 16(6), 557-72. doi: $10.1080 / 14616734.2014 .941884$

Karlin, B. E., Brown, G. K., Trockel, M., Cunning, D., Zeiss, A. M., \& Taylor, C. B. (2012). National dissemination of cognitive behavioral therapy for depression in the department of veterans affairs health care system: Therapist and patient-level outcomes. Journal of Consulting and Clinical Psychology, 80(5), 707-18. doi: 10.1037/a0029328
Karlin, B. E., Trockel, M., Brown, G. K., Gordienko, M., Yesavage, J., \& Taylor, C. B. (2013). Comparison of the effectiveness of cognitive behavioral therapy for depression among older versus younger veterans: Results of a national evaluation. The Journals of Gerontology Series B: Psychological Sciences and Social Sciences, 70(1), 3-12. doi: 10.1093/geronb/gbt096

Leahy, R. L. (2017). Cognitive therapy techniques: A practitioner's guide. New York: Guilford Publications.

Losada, A., Márquez-González, M., Peñacoba, C., \& RomeroMoreno, R. (2010). Development and validation of the Caregiver Guilt Questionnaire. International Psychogeriatrics, 22(4), 650-60. doi: 10.1017/s1041610210000074

Mahoney, R., Regan, C., Katona, C., \& Livingston, G. (2005) Anxiety and depression in family caregivers of people with alzheimer disease: The LASER-AD study. The American Journal of Geriatric Psychiatry, 13(9), 795-801. doi: 10.1097/00019442200509000-00008

McConaghy, R., \& Caltabiano, M. L. (2005). Caring for a person with dementia: Exploring relationships between perceived burden, depression, coping and well-being. Nursing and Health Sciences, 7(2), 81-91. doi: 10.1111/j.1442-2018.2005.00213.x

Pocnet, C., Rossier, J., Antonietti, J.-P., \& von Gunten, A. (2013). Personality features and cognitive level in patients at an early stage of Alzheimer's disease. Personality and Individual Differences, 54(2), 174-9. doi: 10.1016/j.paid.2012.08.035

Salkovskis, P. M. (1989). Cognitive-behavioural factors and the persistence of intrusive thoughts in obsessional problems. Behaviour Research and Therapy, 27(6), 677-82. doi: 10.1016/00057967(89)90152-6

Sappington, A. A. (1989). Adjustment: Theory, research, and personal applications. Salt Lake City: Brooks/Cole Publishing Company.

Seligman, M. E. (1990). Learned optimism: The skills to conquer life's obstacles, large and small. New York: Random House.

Seligman, M. E. P., Schulman, P., \& Tryon, A. M. (2007). Group prevention of depression and anxiety symptoms. Behaviour Research and Therapy, 45(6), 1111-26. doi: 10.1016/j. brat.2006.09.010

Sharf, R. S. (2015). Theories of psychotherapy \& counseling: Concepts and cases. Boston: Cengage Learning. 
